\title{
Study of EMC Test for Large, Permanently-Installed ME Equipment and ME Systems Measured in Situ
}

\author{
Mengchun Song ${ }^{1}$, Weisong $\mathrm{Li}^{1,{ }^{*}}$, Jaye $\mathrm{Chen}^{1}$, Ting $\mathrm{Chen}^{1}$, Yaosheng $\mathrm{Lu}^{2}$ and Renhuan $\mathrm{Yang}^{2}$ \\ ${ }^{1}$ Guang dong Medical Devices Quality Surveillance and Test Institute, Guangzhou, China \\ ${ }^{2}$ Dept. of Electronic Engineering, Jinan University, Guangzhou 510632, China \\ *Corresponding author
}

\begin{abstract}
For large, permanently-installed ME (medical electrical) equipment and ME systems, the EMC (Electromagnetic compatibility) on-site test items and the attentions for each test item are introduced. By analyzing the requirements of CISPR 11 and IEC60601-1-2, the On-site test of electromagnetic radiation disturbance and radiated $\mathrm{RF}$ (radio frequency) electromagnetic fields are elaborated in details.
\end{abstract}

Keywords-large, permanently-installed ME equipment and ME systems; EMC; on-site test; in situ

\section{INTRODUCTION}

The EMC of ME equipment and ME systems attract extensive attention of the whole society due to involving public's health. The implementation of EMC standards are taken more and more seriously during the certification in all countries, which means the ME equipment and ME systems have to meet strict EMC requirements. In China, the EMC standards for $\mathrm{ME}$ equipment and $\mathrm{ME}$ systems have been forcibly implemented, and the EMC requirements are applicable to all ME equipment and ME systems. Generally, ME equipment and ME systems must be tested at the laboratory to verify their conformance to the EMC standards.
While the large, permanently-installed ME equipment and ME systems such as Nuclear Magnetic Resonance, Digital X-ray Photography System, Medical Accelerator etc., cannot be tested at laboratory due to their big size, transportation inconvenience, fixed installation and large rated current. According to the IEC60601-1-2 and CISPR 11, large, permanently-installed ME equipment and ME systems are allowed to be tested at one installation site. Besides, the on-site test is more close to intended use.

Presently, most standards state how to carry out EMC test at the laboratory, but little explains how to test in situ. Besides, the installing and operating environment, configuration of EUT (equipment under test), interconnecting cables, testing point and connection to the electricity supply network of the large, permanently-installed ME equipment and ME systems are complicated, moreover, the uncertainty of ambient noise is considerable, which badly weaken the practicability and repeatability of on-site test. Therefore, study of EMC test for large, permanently-installed $\mathrm{ME}$ equipment and $\mathrm{ME}$ systems measured in situ is greatly beneficial to improve the practicability and repeatability of on-site test and guarantee the effectiveness of test result.

TABLE I. THE EMC ON-SITE TEST ITEMS

\begin{tabular}{|c|c|c|c|c|}
\hline N0. & Item & Requirements & Standard & Remarks \\
\hline \multirow[t]{2}{*}{1} & $\begin{array}{l}\text { Electromagnetic radiation disturbance }(150 \mathrm{k} \sim \\
30 \mathrm{MHz})\end{array}$ & $\begin{array}{l}\text { Magnetic field Quasi-peak }{ }^{\mathrm{a}} \text { : } \\
0.15 \sim 0.49 \mathrm{MHz}, 33.5 \mathrm{~dB}(\mu \mathrm{A} / \mathrm{m}) \\
0.49 \sim 3.95 \mathrm{MHz}, 23.5 \mathrm{~dB}(\mu \mathrm{A} / \mathrm{m}) \\
3.95 \sim 20 \mathrm{MHz}, 8.5 \mathrm{~dB}(\mu \mathrm{A} / \mathrm{m}) \\
20 \sim 30 \mathrm{MHz},-1.5 \mathrm{~dB}(\mu \mathrm{A} / \mathrm{m})\end{array}$ & \multirow[t]{2}{*}{ CISPR 11} & \multirow[t]{2}{*}{$\begin{array}{l}3 \text { m measuring } \\
\text { distance }\end{array}$} \\
\hline & $\begin{array}{l}\text { Electromagnetic radiation disturbance }(30 \mathrm{M} \sim \\
1 \mathrm{GHz})\end{array}$ & $\begin{array}{l}\text { Electric field Quasi-peak } \\
30 \sim 230 \mathrm{MHz}, 50 \mathrm{~dB}(\mu \mathrm{V} / \mathrm{m}) \\
230 \sim 1 \mathrm{GHz}, 57 \mathrm{~dB}(\mu \mathrm{V} / \mathrm{m}) \\
\end{array}$ & & \\
\hline 2 & Electrostatic Discharge & $\begin{array}{l} \pm 2 \mathrm{kV}, \pm 4 \mathrm{kV} \text { and } \pm 8 \mathrm{kV} \text { for air discharge and } \pm 2 \mathrm{kV}, \pm 4 \\
\mathrm{kV} \text { and } \pm 6 \mathrm{kV} \text { for contact discharge }\end{array}$ & IEC 61000-4-2 & 1 \\
\hline 3 & Radiated RF electromagnetic fields & $\begin{array}{l}3 \mathrm{~V} / \mathrm{m} \\
\text { at the selected frequency }\end{array}$ & IEC60601-1-2 & $\begin{array}{c}\text { not life-supporting } \\
\text { ME equipment and } \\
\text { ME systems } \\
\end{array}$ \\
\hline 4 & Electrical fast transients and bursts & $\begin{array}{l} \pm 2 \mathrm{kV} \text { for a.c. and d.c. power lines and } \pm 1 \mathrm{kV} \text { for signal } \\
\text { and interconnecting } \\
\text { cables }\end{array}$ & IEC 61000-4-4 & 1 \\
\hline 5 & Surges & $\begin{array}{l} \pm 0,5 \mathrm{kV}, \pm 1 \mathrm{kV} \text { and } \pm 2 \mathrm{kV} \text { for a.c. power line(s) to earth } \\
\text { and } \pm 0,5 \mathrm{kV} \text { and } \pm 1 \mathrm{kV} \text { for a.c. power line(s) to line (s) }\end{array}$ & IEC 61000-4-5 & 1 \\
\hline 6 & Conducted disturbances, induced by RF fields & $\begin{array}{l}3 \mathrm{Vrms} \text { over the frequency range from } 0.15 \mathrm{MHz} \text { to } \\
80 \mathrm{MHz}\end{array}$ & IEC 61000-4-6 & $\begin{array}{l}\text { not life-supporting } \\
\text { ME equipment and } \\
\text { ME systems }\end{array}$ \\
\hline 7 & Voltage short interruptions & $<5 \% U_{\mathrm{T}}^{\mathrm{b}}$ for $5 \mathrm{~s}$ & IEC 61000-4-11 & l \\
\hline 8 & Power frequency magnetic fields & $3 \mathrm{~A} / \mathrm{m}$ at $50 \mathrm{~Hz}$ & IEC 61000-4-8 & 1 \\
\hline
\end{tabular}




\section{Test Items Of ON-Site TeSt}

According to CISPR 11, under in situ conditions, an assessment of conducted disturbances is not required. large, permanently-installed ME equipment and ME systems shall be classified as group 1 or group 2 and Class A accordance with CISPR 11, which are not intended to be connected to the public mains network based on their intended use. Hence, the test of harmonic distortion and voltage fluctuations and flicker is not required. Usually, large, permanently-installed ME equipment and ME systems with a rated input current exceed $16 \mathrm{~A}$ per phase are exempt from the test of voltage dips. Consequently, the essential test items of on-site test are shown in table 1.

For the measurement on a test site, the electromagnetic radiation disturbance and radiated RF electromagnetic fields are executed at anechoic chamber, which is extremely different from the measurement that is not tested on a radiation test site. So, it is crucial that how to carry out the electromagnetic radiation disturbance and radiated $\mathrm{RF}$ electromagnetic fields in situ, and it will be largely elaborated in this paper. With regard to the other test items, there is smaller difference between On-site test and in situ test. It should be noted that the grounding and power supply are correct to make sure the safety of measuring equipment. For the electrostatic discharge, the temperature and humidity which deviate from the standard requirement should be recorded and the potential influence should be analyzed from the deviation.

\section{EleCtromagnetic RAdiation Disturbance}

\section{A. Ambient Noise}

Owing to the on-site test does not proceed in the shielded chamber, test receiver will receive all kinds of ambient electromagnetic noise, which is from the switch of high power electrical equipment, high voltage transmission line, radio station, TV station, telecommunications and so on. Generally, the ambient noise level is high enough to exceed the specified limit. The emission from EUT is covered by ambient noise, and it is hard to distinguish the electromagnetic radiation from EUT from the ambient noise. Therefore, it is significant to analyze the effects of ambient noise for on-site test.

Before the measurement of electromagnetic radiation disturbance in situ, it is better to close the nearby electronic equipment. Besides, the test site should be far away from arterial traffic, railway, transformer substation, mobile communication station, radio station, airport, port and other equipments which may influence the EUT to insure a pure electromagnetic environment. The other way to reduce the influence of ambient noise is conducting test at non-work time such as middle night when nearby devices are power off. In addition, it is essential to measure the ambient noise every time before measuring the electromagnetic radiation from EUT. Only when the ambient noise can be distinguished, the electromagnetic radiation from EUT can be finally measured.

\section{B. Confirm Measuring Distance}

CISPR 11 specifies that electromagnetic radiation disturbance distance for equipment measured in situ is $30 \mathrm{~m}$. If local conditions do not allow for measurements at $30 \mathrm{~m}$, then a $3 \mathrm{~m}$ or $10 \mathrm{~m}$ distance can be used. In this case, an inverse proportionality factor of $20 \mathrm{~dB}$ per decade shall be used to normalize the measured data to the specified distance for determining compliance, the actual used distance should be recorded at test report. If the level of ambient noise is high, then a closer measuring distance could be chosen, as electromagnetic radiation from EUT is stronger when measuring distance is closer, thus, the influence of ambient noise is weakened. It is remarkable that the measuring distance is between building exterior wall with installation of EUT and antenna. As shown in Figure 1, the distance between the antenna and the exterior wall of shield room is $3 \mathrm{~m}$. Moreover, when measuring large ME equipment and ME systems at $3 \mathrm{~m}$ distance, it is necessary to consider near-field effect at $30 \mathrm{MHz}$. If this near-field effect could not be avoided, a farther distance is needed.

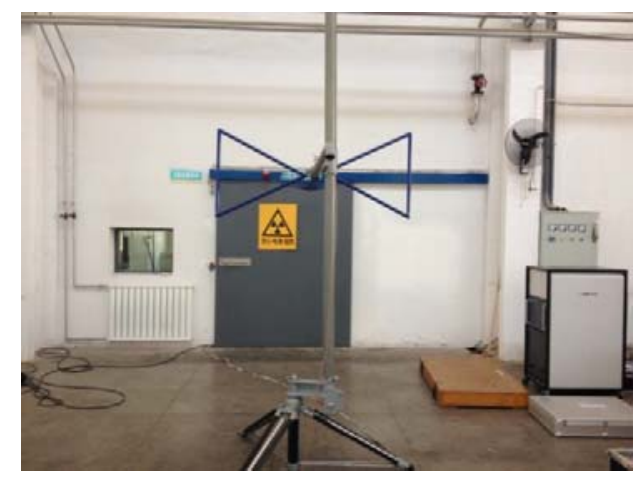

FIGURE I. ELECTROMAGNETIC RADIATION DISTURBANCE MEASUREMENT IN SITU

\section{Configuration of Antennas}

For the measurements on a test site, the test frequency of electromagnetic radiation disturbance range from $150 \mathrm{kHz}$ to 1 $\mathrm{GHz}$. In the frequency range below $30 \mathrm{MHz}$, magnetic field is measured and the corresponding antenna shall be a loop as specified in CISPR 16-1-4. Measurements shall be made for antenna both parallel and perpendicular to EUT. The antenna shall be supported in the vertical plane and be rotatable about a vertical axis. The lowest point of the loop shall be $1 \mathrm{~m}$ above ground level. In the frequency range from $30 \mathrm{MHz}$ to $1 \mathrm{GHz}$, electric field is measured and the antenna used shall be as specified in CISPR 16-1-4. Measurements shall be made for both horizontal and vertical polarization. The nearest point of the antenna to the ground shall be not less than $0.2 \mathrm{~m}$. For measurements in situ the centre of the antenna shall be fixed at $(2.0 \pm 0.2) \mathrm{m}$ height above the ground, no longer vary between $1 \mathrm{~m}$ and $4 \mathrm{~m}$ height.

\section{Confirm Measuring Azimuth}

For measurements on a test site, EUT located on a turntable shall be rotated fully to acquire maximum radiation. For measurements in situ, the large, permanently-installed ME equipment and ME systems could not locate on a turntable, the measurement antenna shall be positioned at various points in azimuth. The number of measurements made in azimuth shall be as great as reasonably practical, but there shall be at least four measurements in orthogonal directions as shown in Figure 2 , and measurements in the direction of any existing radio systems which may be adversely affected. If local conditions 
do not allow for measurements as above, pretesting is beneficial to find maximum radiation at any doubtful direction.

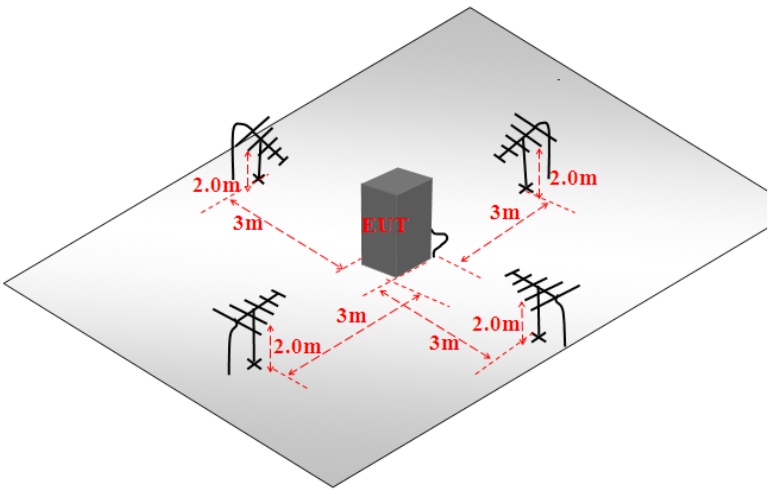

FIGURE II. DIAGRAM OF ANTENNA POSITIONED AT VARIOUS POINTS IN AZIMUTH

\section{E. Operating Mode of EUT}

Attempts shall be made to fully exercise the EUT during testing, if the equipment can operate at several modes, a pretesting at each operating mode is beneficial to get the maximum disturbance operating mode and save plenty of time. Then the EUT shall be final tested under this operating mode to maximize the disturbance. If a given type of equipment can perform separately any one of a number of functions then the equipment shall be tested while performing each of these functions. For systems which may include a number of different components, one of each type of component which is included in the system configuration shall be included in the evaluation. If load conditions of the EUT affect the test result, a dummy load shall be used for the measurements.

\section{F. Configuration of EUT}

Consistent with typical applications of the EUT, the level of the disturbance shall be maximized by varying the configuration of the equipment, such as the banding and position of cables and relative location of different units within the installation. The measurement of an installation in situ will depend on the flexibility inherent in each particular installation. The test report shall contain all the information of configuration.

\section{Measurement of Radiated RF Electromagnetic FIELDS IN SITU}

For the measurement on a test site, radiated RF electromagnetic fields shall be performed in the anechoic chamber. The RF test sources generated from signal generator was amplified by power amplifier and radiated to the space by transmitting antenna to form a uniform field of $3 \mathrm{~V} / \mathrm{m}$. The test shall normally be performed with one side of the EUT exposed to the field, when equipment can be used in different orientations all sides shall be exposed to the field during the test. While for measurement in situ, there is no anechoic chamber and test facilities are impossibly carried to the EUT installation location. Therefore, an alternative test method is necessary.

Large, permanently-installed ME equipment and $\mathrm{ME}$ systems that are constructed in such a way that simulated operation of subsystems is not feasible are exempt from the testing requirements specified by IEC 61000-4-3. If this exemption is used, such large, permanently-installed ME equipment and ME systems are type tested either at one installation site or on an open area test site, using the ambient RF sources (e.g. radio(cellular/cordless) telephones, walkie-talkies, other legal transmitters) that occur in a typical health care environment. In addition, testing is performed in the range $80 \mathrm{MHz}$ to $2,5 \mathrm{GHz}$ at frequencies designated by the ITU for ISM use. The power of, and distance from, the source is adjusted to provide the applicable test level specified in IEC 61000-4-3, with the exception that the actual modulations may be used (e.g. for radio (cellular/cordless) telephones, walkie-talkies).

For a measurement in situ, an exemption is used and the $\mathrm{ME}$ equipment or ME system is not tested for radiated $\mathrm{RF}$ electromagnetic fields over the entire frequency range $80 \mathrm{MHz}$ to $2.5 \mathrm{GHz}$, it is tested only at selected frequencies. The selected frequencies simulate the underlying disturbance for EUT during daily use. The following transmitters and equipment are used as RF test sources.

1) Walkie-talkies, civilian frequency range $409 \mathrm{MHz}$ to $410 \mathrm{MHz}$;

2) GSM mobile radio telephones, frequency range $880 \mathrm{MHz}$ to $915 \mathrm{MHz}$;

3) TD-SCDMA mobile radio telephones, frequency range $1880 \mathrm{MHz}$ to $1900 \mathrm{MHz}$; CDMA2000 mobile radio telephones, frequency range $1920 \mathrm{MHz}$ to $1935 \mathrm{MHz}$; WCDMA mobile radio telephones, frequency range $1940 \mathrm{MHz}$ to $1955 \mathrm{MHz}$;

4) Wireless router, frequency is about $2.4 \mathrm{GHz}$;
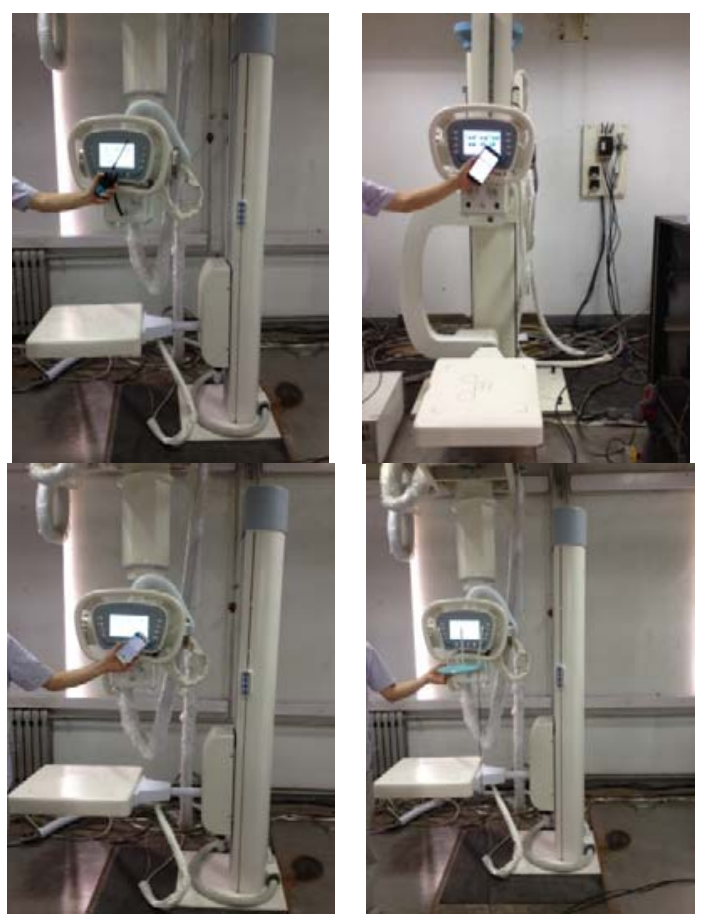

FIGURE III. RF TEST SOURCES OF RADIATED RF ELECTROMAGNETIC FIELDS IN SITU 
The EUT shall be tested under typical installation conditions and normal operation. Attempts shall be made to fully exercise the EUT during testing, and to interrogate all the critical exercise modes selected for the immunity test. The alternative RF test sources shall close to the EUT enough to meet the field intensity specified in standard. As shown in Figure 3, the EUT is tested by different RF test sources. The dwell time of transmitters and equipment shall not be less than the time necessary for the EUT to be exercised and to respond, but shall in no case be less than $3 \mathrm{~s}$. The test shall normally be performed with the transmitters and equipment approaching all sides of the EUT.

\section{ACKNOWLEDGEMENT}

This work was supported in part by projects of Guangdong Science and Technology Program (No. 2015B020233010, 2015B020214004).

\section{REFERENCES}

[1] IEC 60601-1-2 Medical electrical equipment-Part 1-2:General requirements for basic safety and essential performance-Collateral standard: Electromagnetic compatibility-Requirements and tests[S].

[2] CISPR 11 Industrial, scientific and medical equipmentRadio-frequency disturbance characteristics - Limits and methods of measurement[S]. 